\title{
New Approaches to Achieve Close to Zero Carbon Balance in Power Plants
}

\author{
Mikhail Gotovsky ${ }^{1}$, Alexander Gotovsky ${ }^{2}$, Vitaly Lychakov ${ }^{1 *}$, Vladimir Mikhaylov ${ }^{1}$, Yury Sukhorukov ${ }^{1}$, Ekaterina \\ Sukhorukova $^{1}$
}

${ }^{1}$ NPO CKTI JSC, Saint-Petersburg 191167, Russia

${ }^{2}$ Energetic System Consulting, Saint-Petersburg 188309, Russia

Corresponding Author Email: LychakovVD@ckti.ru

https://doi.org/10.18280/ti-ijes.640111

Received: 19 December 2019

Accepted: 17 January 2020

\section{Keywords:}

Fischer-Tropsch process, formate cycle, formic acid, subcritical reactors

\begin{abstract}
The problem of using hydrogen as a coolant became actual before the concept of global warming and the struggle for decarbonization. Formate cycle allows solving problem of transportation and storage. New modified Fisher-Tropsh process. version is described and showed that most rational electromagnetic activation utilization for its implementation. More detailed problem nuclear energy is considered with Carlo Rubbia ideas usage. It is proposed to use subcritical reactor with torium nuclear fuel what ensure $100 \%$ safety. Floating Nuclear Chemical-Synthetic Facility (NChSF) of the open sea was considered.
\end{abstract}

\section{INTRODUCTION}

Currently, the problem of maximum reduction of carbon dioxide emissions into atmosphere is constantly aggravated due to the global campaign to combat global climate change. This struggle requires heavy spending mainly from developed countries.

It should be noted that the use of nuclear energy would make a significant contribution to solving this problem. But modern environmental concepts reject not only carbon-based fuel combustion processes, but also nuclear power. These concepts are based on green political parties, whose role in Western countries is growing steadily and proposed decisions on energy reform are largely taken under their pressure.

The idea of obtaining clean energy, outlined below, is based on the following provisions:

(1) The doctrine of global warming under the influence of technogenic greenhouse gases is essentially a hypothesis that can hardly be considered as convincingly proven. Among its opponents are a number of experts in the field of geophysics.

(2) In the modern history of science, waves of fashionable environmental anxiety have already appeared on the basis of hypotheses that later turned out to be speculative (a typical example is the doctrine of the expansion of ozone holes under the influence of freons, which its authors prefer to keep silent about) but are extremely costly.

With this in the mind, those that remain relevant even if today's global warming doctrine is to be corrected are preferred.

A summary of the technology concept proposed by authors related to green energy, which allows to reduce $\mathrm{CO}_{2}$ emissions or to reduce the concentration of $\mathrm{CO}_{2}$ in atmosphere, without requiring such a high cost. In other words: a concept that can be considered in the context of combating climate change, but remaining relevant outside this context, simply as one of the energy-chemical technologies based on a renewable source of raw materials - atmospheric $\mathrm{CO}_{2}$.

The authors have already published a number of works in which various aspects of the problem are considered [1-3]. The basis of the proposed approaches is the use of formic acid obtained from atmospheric $\mathrm{CO}_{2}$ in the so-called formate cycle. Therefore, we will begin by describing the proposed options for implementing this process.

Formic acid ( $\mathrm{HCOOH})$ was first obtained from red forest ants (which is why it got its name) in the 17th century. Also, in nature, it is found in some plants, for example, nettles and needles, and in the caustic secretions of bees. Usually it is obtained chemically in the production of acetic acid as a byproduct.

\section{A BRIEF DESCRIPTION OF THE SIMPLE APPROACHES WHICH CAN BE USED TO PRODUCE FORMIC ACID FROM CO}

\subsection{The raw material for producing formic acid}

In the proposed formate cycle $\mathrm{CO}_{2}$ is extracted from fuel gases or from atmosphere. The production of $\mathrm{CO}_{2}$ from atmospheric air can be organized in a cyclic process of liquid chemisorption. As a sorbent can be used, in particular

\subsubsection{An aqueous solution of potassium carbonate}

Upon contact with air at ordinary temperatures and elevated pressure, carbon dioxide passes into solution with the formation of potassium hydrogen carbonate. With a decrease in pressure, hydrocarbonate decomposes with the release of $\mathrm{CO}_{2}$. The selection process is almost complete when the temperature rises to 100 degrees Celsius.

\subsubsection{An aqueous solution of amino alcohol (ethanolamine or methanolamine)}

At ordinary temperature and pressure, $\mathrm{CO}_{2}$ is absorbed with the formation of the hydrocarbonate of the corresponding amino alcohol, and when heated to $60^{\circ} \mathrm{C}, \mathrm{CO}_{2}$ is released.

Both of these processes are well studied. 
Reversible sorption of $\mathrm{CO}_{2}$ by specialized solid (granular) absorbers (including some types of zeolite) is also possible.

There are gas-membrane methods for separating $\mathrm{CO}_{2}$ from other air components, however, to date, this promising technology has not been sufficiently developed for practice.

The choice of a specific technology for the reversible sorption of $\mathrm{CO}_{2}$ from air is determined based on the technical and economic conditions of production and does not affect the further stages of the formate cycle.

\subsection{Electrochemical reaction at the beginning of the formate cycle}

Production of formic acid by reduction from carbon dioxide in an aqueous solution (hydrogen source is water):

A wide range of possible structures of electrodes and catalysts for a reaction in an aqueous medium was studied using an electrochemical scheme:

$$
\mathrm{CO}_{2}+2 \mathrm{H}(+)+2 \mathrm{e}->\mathrm{HCOOH}
$$

Or

$$
\mathrm{CO}_{2}+\mathrm{H}_{2} \mathrm{O}+2 \mathrm{e}->\mathrm{HCOO}(-)+\mathrm{OH}(-)
$$

where, $\mathrm{HCOO}(-)$ - formate ion - dissociated formic acid.

We studied, in particular, the use of electricity obtained directly from solar panels. This is the perfect green method for absorbing $\mathrm{CO}_{2}$ from atmosphere.

\subsection{Direct catalytic hydrogenation of $\mathrm{CO}_{2}$}

It was made by external hydrogen source using reaction:

$$
\mathrm{CO}_{2}+\mathrm{H}_{2}->\mathrm{HCOOH}
$$

The most promising in terms of speed and degree of conversion is the reaction of hydrogen with $\mathrm{CO}_{2}$ in a supercritical state in the presence of a homogeneous catalyst.

\subsection{Direct electrochemical production of formic acid using solar panels}

Scientists from the University of Prison have developed a unique way of converting solar energy into biofuel. The transformation of carbon dioxide and water into formic acid was carried out using special solar panels. These goals were set by a team led by Andrew Bockarsley of the Chemistry Laboratory at Princeton University. The transition of carbon dioxide and water to formic acid was carried out using solar panels [4]. By stacking three electrochemical cells together, scientists were able to achieve high energy efficiency - twice as much as energy efficiency in natural photosynthesis.

Formic acid is currently used in many fuel cells. Experts suggest that the widespread use of formic acid in the fuel industry may eventually displace some traditional fuels.

\section{APPLICATION OF FORMIC ACID AS A HYDROGEN STORAGE BATTERY}

Reversibility of the chemical hydrogenation of $\mathrm{CO}_{2}$ to formic acid (i.e., the possibility of reverse dehydrogenation) allows the use of the $\mathrm{CO}_{2}<->\mathrm{HCOOH}$ system as a hydrogen battery. There are research works on carrying out both reactions (direct and reverse) in one reaction-catalytic system. Reaction

$$
\mathrm{HCOOH}=\mathrm{CO}_{2}+\mathrm{H}_{2}
$$

proceeds with the use of modern catalysts under relatively mild conditions. That allows to place a container with formic acid (as a hydrogen accumulator) and a compact catalytic reactor to extract hydrogen from it directly at the point of hydrogen consumption.

Special cylinders are not required for storage of formic acid, and the mass fraction of hydrogen in formic acid is $4.34 \%$, more than $3 \%$, at which the hydrogen accumulator is considered technically and economically acceptable

\section{FORMATE CYCLE USAGE IN GREEN ENERGY}

\subsection{Chemical and technological background of the formate cycle}

In any chemical (or electrochemical) synthesis process being developed for mass use, the issue of catalyst is critical.

This applies both to the catalyst manufacturing technology and to the workflow itself in which the catalyst is used. The catalyst should:

(1) Do not require ultra-expensive or knowingly rare raw materials for production.

(2) Do not require ultra-complex and ultra-expensive technologies for production.

(3) Do not require exotic working conditions for temperature and pressure.

(4) Do not create a high risk in production and especially in the work process.

(5) Have sufficient resistance to the state of the work environment.

(6) Have sufficient durability under normal operating conditions

Modern research in this area of catalysis is focused primarily on organic complex compounds of "light" metals of group VIII, in particular iron (Figure 1). The result is a complex that provides a voltage close to the cell on the platinum catalyst. The possibility of its mass production is undeniable.

The decomposition of formic acid with the evolution of hydrogen on a catalyst, a complex compound of iron, was demonstrated at the Catalysis Institute in Rostock (Figure 2). This is extremely important in terms of the use of formic acid as a hydrogen accumulator.

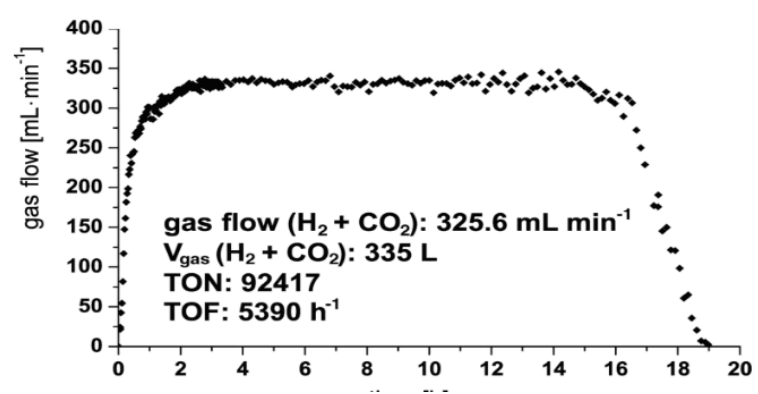

Figure 1. Experimental results of continuous process for hydrogen extraction from formic acid [5] 


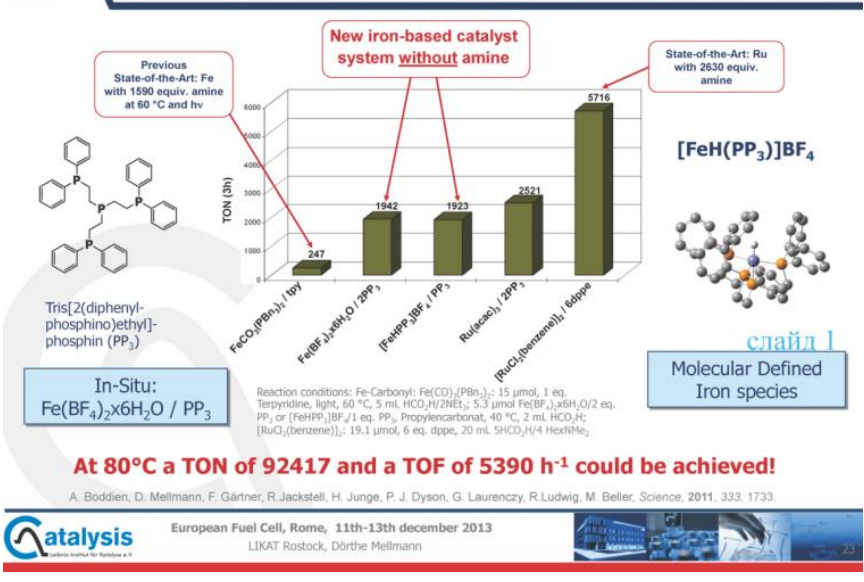

Figure 2. Iron Catalyzed Dehydrogenation of $\mathrm{HCOOH}[5]$

\subsection{Electrochemical formate synthesis: processes and criteria}

The electrochemical production of formic acid by the method of $\mathrm{CO}_{2}$ reduction at the cathode has been known for a long time. The process can be implemented on different cathodes of different composition, and under different conditions. Optimization in three directions is interesting:

1) Maximum - maximum yield of formic acid per unit area of the cathode.

2) Minimum energy consumption - carrying out the process at a low temperature (below $100^{\circ} \mathrm{C}$ )

3) The reversibility of the process - the ability to create a battery, which in charging mode, it restores $\mathrm{CO}_{2}$ to formic acid, and in discharge mode, it oxidizes formic acid to $\mathrm{CO}_{2}$, using one catalytic electrode as a cathode in the charging phase, and the anode in the discharge phase.

The multivariance of electrochemical synthesis is one of the reasons why formic acid looks like a promising renewable energy carrier and an agent for storing hydrogen. The second serious reason is the high current density in formic acid fuel cells. It is much higher than the current density for a similar oxidation of alcohols. But it should be noted that the energy density for formic acid is significantly lower than that of methanol $(5.6 \mathrm{KJ} / \mathrm{g}$ versus $22.7 \mathrm{KJ} / \mathrm{g})$. The third reason is the additional use of formic acid as a starting material for organic synthesis chains. For this reason, it makes sense to dwell in more detail, having previously noted that formic acid is both a source of hydrogen and sources of pure carbon monoxide-II, $\mathrm{CO}$, which is released by the reaction: $\mathrm{HCOOH}$ $\rightarrow \mathrm{CO}+\mathrm{H}_{2} \mathrm{O}$

\section{FORMATE FT (FISHER-TROPSCH) PROCESS FOR PRODUCING TRADITIONAL ENERGY PRODUCTS WITH ZERO CARBON BALANCE}

In the papers $[1,2]$, it was noted that the "formate cycle" can serve as a promising general scheme for the processes of obtaining green fuel and products with a minus carbon effect. The basis of the formate cycle is the electrochemical production of formic acid from water and atmospheric $\mathrm{CO}_{2}$.

$$
\mathrm{CO}_{2}+2 \mathrm{H}_{2} \mathrm{O}+2 \mathrm{e}->\mathrm{HCOOH}+2 \mathrm{OH}(-)
$$

This process was laboratory-scaled to a level even more energy-efficient than natural photosynthesis (i.e., than the process by which plants bind $\mathrm{CO}_{2}$ in the form of carbohydrates). The resulting formic acid can be used, in particular, as an intermediate for the synthesis of green fuels with zero carbon balance, and synthetic chemical organic products with a minus carbon effect.

Recently, attention has been paid to the possibility of the formic acid catalytic conversion into components of the synthesis gas necessary for the Fischer-Tropsch process.

$$
\begin{aligned}
& \mathrm{HCOOH}->\mathrm{CO}_{2}+\mathrm{H}_{2} \\
& \mathrm{HCOOH}->\mathrm{H}_{2} \mathrm{O}+\mathrm{CO}
\end{aligned}
$$

In this case, the quality of the synthesis gas obtained in this way will be significantly higher than in the original process of the 1920s - 1940s. In the case of the formate cycle, synthesis gas will not contain any catalytic poisons and other components that reduce the selectivity of the FT- process, which will allow the use of a number of existing developments that require high purity at the inlet.

Interesting to add that recently formed Canadian clean energy company "Carbon Engineering" focusing on the commercialization of technology for capturing $\mathrm{CO}_{2}$ directly from the atmosphere. This captured $\mathrm{CO}_{2}$ can either be stored underground or converted into carbon-neutral fuel using renewable energy sources. Semi-industrial production launched this year (2019) at the plant in Squamish.

For mentioned approach implementation three separate stages are needed:

(1) The release of hydrogen from formic acid.

(2) Isolation of carbon monoxide from formic acid.

(3) The actual Fischer-Tropsch process.

A more rational (with the exception of one stage) would be the direct use of formic acid, without first isolating carbon monoxide.

From the physical chemistry point of view the process under consideration, it is necessary to take into account the relatively low reactivity of formic acid in comparison with carbon monoxide. There is a traditional way of activation - by applying high temperatures, high pressures in the gas phase, and specific catalysts, however, the way of electromagnetic activation may be more interesting. This approach is analyzed in details in our paper [3].

\subsection{Prospects of Electromagnetic Activation usage}

A significant amount of data on reactions of this kind of organic synthesis has been accumulated since 1953, from experiments by Stanley Miller and Harold Urey. We can talk about the presence of a mixed effect of classical catalysis and electric field initiation of a series of chemical reactions with the formation of new carbon-carbon bonds in the region of locally high field strength on a solid inorganic surface. This can serve as a starting point for the development of technological methods of the discussed modified FT process, based on the direct gas-phase reaction of formic acid with hydrogen, using a combination of inexpensive catalysts and an electric field.

Such methods theoretically open up the possibility of not only the reaction of formic acid with hydrogen, but also for the reaction with the third component: $\mathrm{CO}_{2}$. Under ordinary conditions, carbon in a $\mathrm{CO}_{2}$ molecule exhibits low reactivity, 
in particular, due to the symmetry of the molecule and zero dipole moment.

However, electromagnetic activation can lead to a change in the configuration of electronic orbitals, and a deviation of the molecule from a strictly linear structure. In this case, we can assume the passage of the reaction in a three-component system:

$\mathrm{HCOOH}+\mathrm{CO}_{2}->\mathrm{HOOC}-\mathrm{COOH}$ (formation of oxalic acid)

$\mathrm{HOOC}-\mathrm{COOH}+\mathrm{H}_{2}->\mathrm{HOOC}-\mathrm{CHO}+\mathrm{H}_{2} \mathrm{O}$ (reduction to glyoxylic acid, which already has a high reactivity).

Also, for any of the two types of electromagnetic activation discussed, it is highly likely to assume a parallel reaction:

$$
\mathrm{CO}_{2}+\mathrm{H}_{2}->\mathrm{HCOOH}
$$

In the given three-component system, an additional mole of $\mathrm{CO}_{2}$ per mole of $\mathrm{HCOOH}$ can be organized into the FT process, and an additional amount of hydrogen can be involved in the binding of $\mathrm{CO}_{2}$, which greatly increases the efficiency of the process for utilization of atmospheric carbon dioxide (increase in negative "carbon balance").

An exception would also be useful for the second preliminary stage - hydrogen evolution from formic acid. Such an optimal analogue of the Fischer-Tropsch process would be redox disproportionation of formic acid (dismutation, asymmetrization of the starting material with hydrogen).

At the level of chemical reactions, such a process would have the form:

$$
3 \mathrm{HCOOH}->-\mathrm{CH}_{2-}+2 \mathrm{CO}_{2}+2 \mathrm{H}_{2} \mathrm{O}
$$

The closest of the laboratory-studied processes is the disproportionation (dismutation) of benzoic acid or its salts in the presence of a catalyst:

$$
\mathrm{C}_{6} \mathrm{H}_{5} \mathrm{COOH}->\mathrm{C}_{6} \mathrm{H}_{6}+\mathrm{C}_{6} \mathrm{H}_{4}(\mathrm{COOH})_{2}
$$

Redox disproportionation of carbon monoxide is also known

$$
2 \mathrm{CO}->\mathrm{C}+\mathrm{CO}_{2}
$$

And redox disproportionation of formaldehyde:

$$
2 \mathrm{HCHO}+\mathrm{H}_{2} \mathrm{O}->\mathrm{CH}_{3} \mathrm{OH}+\mathrm{HCOOH}
$$

Here is an example of experimental work devoted to the problem under consideration [6].

The test rig (Figure 3) was designed to study chemical activation in a cold plasma above a liquid mirror during an electric discharge through gas and liquid:

- in a flash corona discharge $\mathrm{U}=10 \mathrm{kV}, \mathrm{I}=10 \mathrm{~mA}, \mathrm{n}=100$ $\mathrm{kHz}$

- in the nanosecond streamer discharge $\mathrm{U}=75 \mathrm{kV} \mathrm{I}=80 \mathrm{~A}$, $\mathrm{n}=0.1 \mathrm{~Hz}$

The stand is a 2.5-liter cylindrical glass container with a diameter of $12 \mathrm{~cm}$ and a height of $22 \mathrm{~cm}$. The thickness of the liquid layer was $1-10 \mathrm{~cm}$. One electrode was fixed in the bottom of the container, the second passed through the lid and the distance from it to the liquid surface was $0.6 \mathrm{~mm}$ for corona discharge and $5.5 \mathrm{~cm}$ for streamer discharge.

During the experiments, the dependences of the yield of free radicals in the air-water mixture were shown. The catalytic effect of radicals was confirmed (since the yield of secondary substances exceeded the so-called "Faraday", i.e. calculated by the one-act reaction of a free radical.).

It should be noted that the second of the known paths of the Fischer-Tropsch process

$2 \mathrm{CO}+\mathrm{H}_{2}->-\mathrm{CH}_{2}-+\mathrm{CO}_{2}$ is in part a disproportion.

Also, partly disproportionate will be its possible modification, discussed above:
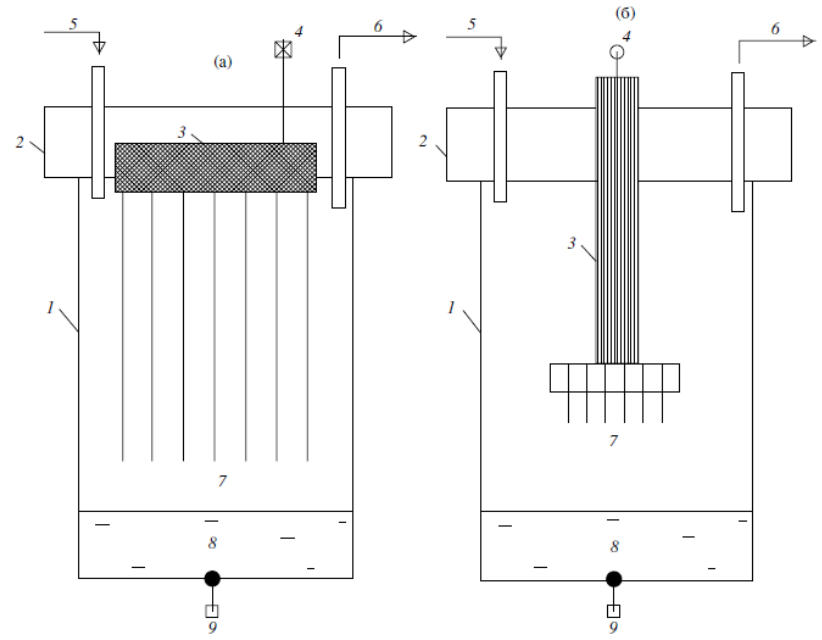

Figure 3. Sketch of a reactor for studying active electrical discharge factors [6]. flash corona discharge, (b) nanosecond streamer discharge

$$
2 \mathrm{HCOOH}+\mathrm{H}_{2}->-\mathrm{CH}_{2^{-}}+\mathrm{CO}_{2}+2 \mathrm{H}_{2} \mathrm{O}
$$

The practical steps to develop the technology of a new (formate) FT process can be a laboratory bench test of possible reaction paths. Such paths are considered in the paper [3].

The final choice of the method based on the results of bench research should be made on the basis of a comprehensive criterion for the speed of passing the modified FT process.

\section{POSSIBILITIES OF NUCLEAR ENERGY USAGE FOR SOLUTION PROBLEMS UNDER CONSIDERATION}

A more or less objective analysis of the prospects for fulfilling the widely discussed plans for changing the energy structure shows that they cannot be fulfilled without using the capabilities of nuclear energy, which objectively ensures the reduction of $\mathrm{CO}_{2}$ emissions into the atmosphere. However, obstacles mentioned above interfere the realization of these opportunities. They are especially significant for the developed countries of the West. Here we briefly consider the possibilities of overcoming them, taking into account the developed concept of the formate cycle.

\subsection{Nuclear formative energy}

The complex of socio-economic causes of modern nuclear energy problems can be divided into four groups of factors.

(1) The problem of safety, actually NPP.

(2) The problem of the safety of production and transportation of nuclear fuel.

(3) The problem of transportation and disposal of spent nuclear fuel (SNF) 
(4) The problem of disposal of irradiated reactor structures.

Of course, there are risks in nuclear power, but since the 1980s, the anti-nuclear lobby has held a series of PR events in which nuclear power was demonized. Due to the occurrence of radiophobia (nucleophobia), the safety requirements in nuclear power were unreasonably high. The potentially low price of electricity produced at nuclear power plants was extremely high. A number of nuclear power plants were closed for political reasons, and a number of new nuclear power plant projects were phased out. Even the campaign against fossil hydrocarbon fuels as part of the fight against $\mathrm{CO}_{2}$ emissions did not lead to a renaissance in nuclear power.

But, on the other hand, overstated expectations, fueled by investment in wind generators and solar panels for 20 years, give way to reasonable skepticism. They will not be able to replace thermal power plants in the near future. There is a request for new classes of nuclear power plants, as free as possible from the four factors listed above. In this paper, we will try to formulate the concept of such a nuclear power plant - a nuclear chemical-synthetic facility (NChSF)

\subsection{Abstracts of offshore energy}

First of all, this is the floating NChSF of the open sea. Not being located in the inhabited territory, or in the coastal waters, such NChSF is spared from the first factor. NChSF supplies the produced energy not by transferring power to power lines, but by synthesis and shipment of a convenient, safe and sufficiently universal energy carrier, which is produced at NChSF. In the proposed concept, it is formic acid, which is synthesized electrochemically from water and atmospheric $\mathrm{CO}_{2}$. The technology for the production of formic acid by fixing $\mathrm{CO}_{2}$ with alkali in an aqueous bicarbonate solution, and subsequent electrolysis reduction, has been known since 1869 . Today, a number of advanced technologies are known but this does not change the essence of the matter.

Formic acid is safe to transport and can be used:

- As a transit hydrogen accumulator for hydrogen energy.

- For the synthesis of ersatz gasoline in a modified FischerTropsch process.

- By itself, as an energy carrier for fuel cells.

The design of the floating NChSF should not include expensive materials, as well as fragments that require expensive and / or complex technology for the manufacture. This allows to vary the life of the reactor and its parts, especially those irradiated in the core more flexibly.

The floating NChSF should be extremely "omnivorous", and use mainly cheap and / or common types of nuclear fuel.

- Natural uranium (including biotechnologically extracted from sea water).

- Natural thorium.

- SNF

- Weapons-grade plutonium to be disposed of.

- Excess depleted uranium.

It is necessary that the floating nuclear fuel storage facility provide deep afterburning of nuclear fuel, leaving mostly isotopes with atomic mass 60 - 130 in the liquid phase (in the form of an aqueous solution) as waste, which simplifies the process of removal from the core. It is assumed that the $\mathrm{NChSF}$ reactor operates in a continuous or semi-continuous mode, with the addition of nuclear fuel as it burns. Disposing of such waste in the high seas in a safe way is not a significant challenge.
Based on the foregoing, the subcritical reactor (Karl Rubbia's concept [7]), but with a water-solution core, is seen as optimal. In this case, the creation of an additional neutron flux for the implementation of efficient fission in nuclear fuel can be realized through a non-isotopic neutron source - a plasma focus lamp, or a modified Farnsworth - Hirsch fusor.

Plasma focus is an intensive source of various radiation: neutron, $\mathrm{x}$-ray, etc. in a wide range of changes in the characteristics of the spectrum

Fusor is a well-controlled neutron source with no residual radioactivity. Because the "active zone" of the fusor is a spherical region, the production of a directed neutron flux is provided by the manufacture of a special "window" in the case.

The design and operation of such a reactor were largely investigated in the course of work to prevent undesirable selfsustaining chain reactions. A significant part of such work relates specifically to tanks with aqueous solutions of nuclear waste.

Of course, the thermal parameters of such a reactor will be low, but sufficient for the stated purposes. The power generating unit can be built according to various schemes from a low-pressure turbine to a reciprocating steam engine, or an air-to-heat Stirling machine.

\subsection{A brief description of the floating nuclear chemical- synthetic installation (NChSF) of the open sea}

(1) The minimum price of the carrier ship with high reliability and resistance to destructive factors, probable or inevitable at sea.

It is proposed to use the long-known class of sea transport "Liberty" as a carrier ship in the version with concrete (armocement case). Maritime transport Liberty was used as a carrier for the MH1-A (floating nuclear power plant manufactured in the USA, 1960s). The concrete version of Liberty was built in a large series in the 1940s, and showed high reliability and durability at an extremely low price.

(2) The maximum flexibility of nuclear fuel storage facilities in relation to nuclear fuel, the possibility of using various types of nuclear fuel without its high-tech training. Cheap and / or common types of nuclear fuel which were enumerated above.

(3) The minimum price and minimum technological complexity of NChSF with high safety and resistance to emergency failures and to personnel errors.

(4) Subcritical reactor with a homogeneous watersolution core.

Currently, interest in small reactors (of the order of $1 \mathrm{MW}$ thermal power) with a similar core is returning

In such reactors (of the Argus type), solutions of enriched uranium salts are used that provide self-sustaining chain reaction (SSCR) i.e. critical neutron parameters. Higher corrosion from molten salts. The proposed embodiment implements a subcritical process. Moreover, the creation of an additional neutron flux for efficient fission in nuclear fuel can be realized through a non-isotopic neutron source. As follows indirectly from a number of published data, the effective operation of a small subcritical reactor with a concentrated aqueous solution of fissile material requires no more than 1015 neutrons per second per $\mathrm{cm}^{2}$. In modern non-isotopic sources, the possibility of achieving a neutron flux of $1017-1018$ / s $\mathrm{cm}^{2}$ is shown.

The thermal parameters of such a reactor will be low, but sufficient for the stated purposes. Actually, the power 
generating unit can be built according to various schemes from a low-pressure turbine to a reciprocating steam engine, or an air-heat Stirling machine.

(5) Minimum technical complexity and price for the disposal of spent nuclear fuel of nuclear fuel storage facilities, subject to reasonable environmental protection requirements.

SNF can be disposed of in the open sea through the production of concrete monoliths from a dry mix delivered from the shore and an aqueous solution discharged from the core. After curing, the monolith can be flooded at depths of 2000 meters, without any consequences for the exploited biological marine resources, and without any risk to personnel and passengers on high seas ships.

(6) The minimum technological complexity of the synthesis of the target chemical product, the minimum biological and technical hazard of the product, the minimum transportation requirements. Maximum product versatility when using it.

In the proposed concept, it is formic acid, which is synthesized electrochemically from water and atmospheric $\mathrm{CO}_{2}$. The technology for the production of formic acid by fixing $\mathrm{CO}_{2}$ with alkali in an aqueous bicarbonate solution, and subsequent electrolysis reduction, has been known since 1869. Today, a number of advanced technologies are known. but this does not change the essence of the matter. Formic acid is safe to transport and can be used:

- As a transit hydrogen accumulator for use in hydrogen energy.

- For the synthesis of ersatz gasoline in a modified FischerTropsch process.

- By itself, as an energy carrier for fuel cells.

(7) Additional options NChSF having high socially positive value and good PR.

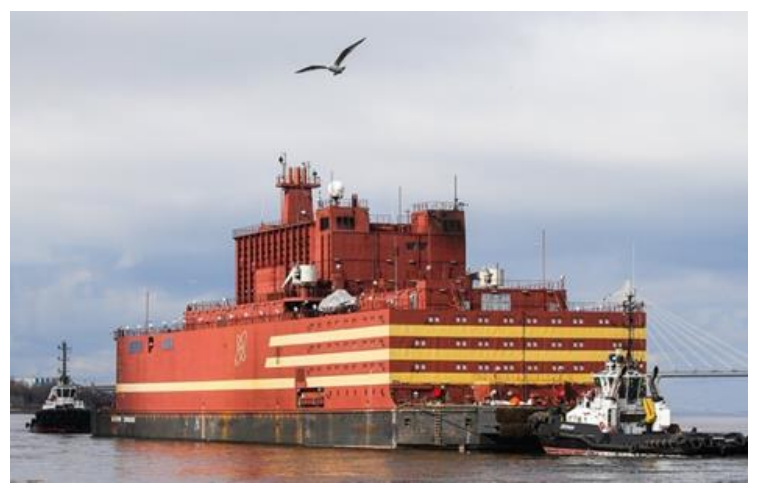

Figure 4. FNPP "Academician Lomonosov"

In this regard, it is proposed to equip NChSF with a simple desalination plant. Corresponding experience is available for FNPP "Academician Lomonosov" (Figure 4):

Productivity 240,000 cubic meters of fresh water per day (with a thermal capacity of $300 \mathrm{MW}$ ).

\section{CONCLUSIONS}

The paper outlines approach that provides the solution to the following cardinal tasks in the framework of creating an autonomous power plant with a carbon balance close to zero:

(1) Production of hydrogen fuel without the need for high temperature installation.

(2) Solving the problem of transporting and storing hydrogen using formic acid.

(3) Usage of the floating Nuclear Chemical - Synthetic Facility (NChSF) of the open sea.

Not being located in the inhabited territory, or in the coastal waters, such NChSF have not safety problems. NChSF does not deliver the generated energy by power transmission lines, but by synthesizing and shipping a convenient, safe and reasonably versatile energy carrier that is produced at NChSF.

In the proposed concept, it is formic acid, which is synthesized electrochemically from water and atmospheric $\mathrm{CO}_{2}$.

This facility uses mainly cheap and / or common types of nuclear fuel and permits to have closed nuclear cycle.

Besides NChSF system can be used for the synthesis of ersatz gasoline in a modified Fischer-Tropsch process.

\section{REFERENCES}

[1] Gotovsky, M., Gotovsky, A., Mikhailov, V., Kolpakov, S., Lychakov, V., Sukhorukov, Y. (2018). Formic acid cycle as partial alternative to Allam cycle less expensive and simpler. TI-IJES, 61+1(2): 49-54.

[2] Gotovsky, M., Gotovsky, A., Mikhailov, V., Kolpakov, S., Lychakov, V., Sukhorukov, Y., Sukhorukova, E. (2019). Formate FT-process for producing traditional energy carriers with zero carbon balance. WIT Transactions on Ecology and the Environment, 237: 155162. https://doi.org/10.2495/ESUS190141

[3] Gotovsky, M., Gotovsky, A., Mikhailov, V., Lychakov, V., Sukhorukov, Y., Sukhorukova, E. (2019). Formate cycle ICEBE 2019. Conference Abstracts, Singapore, p. 29.

[4] Watkins, J.D., Bocarsly, A.B. (2014). Direct reduction of carbon dioxide to formate in high-gas-capacity ionic liquids at post-transition-metal electrodes. Chemsuschem, 7(1): 284-290. https://doi.org/10.1002/cssc.201300659

[5] Boddien, A., Mellmann, D., Gartner, F., Jackstell, R., Junge, H., Dyson, P.J., Laurenczy, G., Ludwig, R., Beller, M. (2011). Efficient dehydrogenation of formic acid using an iron catalyst. Science, 333(6050): 1733-1736. https://doi.org/10.1126/science. 1206613

[6] Aristova, N.A., Piskarev, I.M., Ivanovsky, A.V., Selemir, V.D., Spirov, G.M., Shlepkin, S.I. (2004). Initiation of chemical reactions under the influence of electric discharge solid dielectric system - gas - liquid. Journal of Physical Chemistry, 78(7): 1326-1331.

[7] Fernandez, R., Mandrillon, P., Rubio, J.A., Rubbia, C. (1996). A preliminary estimate of the ecomomic impact of the energy amplifier. European Organization for Nuclear Research. CERN/LMS/96-01 (EET). http://cds.cern.ch/record/297967 